\title{
Megakaryocytic alterations in bone marrow aspiration smears in thrombocytopenia
}

\author{
Anuja Bhandari ${ }^{1,2}$, Anil Dev Pant ${ }^{2}$, Anjan Shrestha ${ }^{2}$, Jiwan Thapa ${ }^{3}$ \\ ${ }^{1}$ Department of Pathology, National Academy of Medical sciences, Bir hospital, Kathmandu, Nepal \\ ${ }^{2}$ Department of Pathology, Institute of medicine, Tribhuwan University Teaching Hospital, Kathmandu, Nepal \\ ${ }^{3}$ Department of Medicine, National Academy of medical sciences, Bir hospital, Kathmandu, Nepal
}

\section{Keywords: \\ Megakaryocytes; Morphology; \\ Thrombocytopenia;}

\begin{abstract}
Background: Thrombocytopenia can be seen in any patients irrespective of age and the causes are diverse. This study was done to determine the frequency of various conditions associated with thrombocytopenia and to assess the number and morphology of megakaryocytes in various cases of thrombocytopenia. Megakaryocytic alterations in myelodysplastic versus non-myelodysplastic conditions were also evaluated in this study.
\end{abstract}

Materials and methods: This was a prospective study conducted on 132 cases of bone marrow aspirates of thrombocytopenia over a duration of one year from 14th April 2017 to 13th April 2018 in Tribhuvan University Teaching Hospital, Kathmandu. All the statistical evaluation was done by using SPSS version 24.

Results: In this study of 132 cases, megakaryocytic thrombocytopenia was the most common cause of thrombocytopenia for which bone marrow aspiration was done. The most common dysplastic change observed in megakaryocytes was micro megakaryocyte which was more commonly seen in MDS. Nondysplastic changes frequently observed were immature forms followed by bare nuclei and were more frequently seen in megakaryocytic thrombocytopenia followed by in myelodysplastic syndromes.

Conclusions: Many similar morphological changes were observed in megakaryocytes among different hematological diseases. So, the presence of dysplastic megakaryocyte should not prompt an interpretation of myelodysplastic syndromes and should always be correlated with patient's clinical and hematological parameter.

\section{Correspondence:}

Dr. Anuja Bhandari, $M D$

Department of Pathology,

National academy of medical sciences, Bir hospital, Kathmandu, Nepal ORCID ID: 0000-0001-6211-591X

Email:anuja2071@yahoo.com

Received : July $16^{\text {th }} 2019 ;$ Accepted : August $28^{\text {th }} 2019$

Citation:Bhandari A, Pant AD, Shrestha A, Thapa J. Megakaryocytic alterations in bone marrow aspiration smear in thrombocytopenia. J Pathol Nep. 2019;9: 1523-9. DOI 10.3126/jpn.v9i2.25408

Copyright: This is an open-access article distributed under the terms of the Creative Commons Attribution 4.0 International License, which permits unrestricted use, distribution, and reproduction in any medium, provided the original author and source are credited.

\section{INTRODUCTION}

Megakaryocytes are the largest hematopoietic cells in the bone marrow with size ranging from 40 to $100 \mathrm{um}$. Nucleus is large with multiple contiguous lobes and cytoplasm is pinkish blue with numerous reddish blue granules. ${ }^{1}$ Megakaryocytes (MK) are derived from haematopoietic stem cells (HSCs). These stem cells are located in the marrow sinusoids and depending upon the signals they are capable of producing all types of blood cells. Thrombopoietin is the primary signal for megakaryocyte production. ${ }^{2}$

The hallmarks of MK maturation are endo-reduplication 
(polyploidisation) and expansion of cytoplasmic mass. The megakaryocytes require an intricate series of remodeling events for the production of platelets. Thousands of platelets are released from a single megakaryocyte. ${ }^{3}$ Any abnormalities in this process results in clinically significant disorders and inappropriate platelet production is one among them. ${ }^{4}$

Thrombocytopenia is defined as platelet counts less than $150,000 / \mu 1$. A normal human platelet count ranges from 150,000 to 450,000 platelets per microliter of blood. Usually thrombocytopenia has no symptoms and is found on a routine full blood count. When the platelet counts are less than $30,000 / \mu 1$, patient suffers from spontaneous bruising and purpura or with continuous/relatively long-lasting bleeding from injuries and wounds. Until the platelet count is less than $10,000 / \mu 1$, clinically significant spontaneous bleeding does not usually occur. Thrombocytopenia is a very common condition for which bone marrow aspiration is done. ${ }^{5}$ Thrombocytopenia may be due to one of three reasons: a) Decreased production of platelets b) Increased destruction of platelets and c) Changing of distribution of platelets. $^{6}$

Thrombocytopenia may be a presenting feature in various hematological disorders like acute myeloid leukemia, chronic lymphocytic leukemia, aplastic anemia, myelodysplastic syndrome, multiple myeloma. Immune thrombocytopenic purpura (ITP), megaloblastic anemia, aplastic anemia and leukemia are common causes of thrombocytopenia. ${ }^{5}$

Bone marrow examination helps to differentiate cases of decreased platelet production from cases of peripheral platelet destruction. It also helps to differentiate the number, size and maturity of the megakaryocytes. The ultimate aim of bone marrow examination is to achieve a definite diagnosis with reasonable accuracy using a minimally invasive technique. In addition to microscopic evaluation of the cells and structure, additional tests may be performed, depending on the purpose for testing like immunohistochemistry, flow cytometry and cytogenetic studies. The procedure's low complication rate is an additional advantage that allows bone marrow aspiration to be performed as an outpatient procedure. It is also a suitable procedure when patients are debilitated or having multiple lesions.

Various megakaryocytic alterations in bone marrow aspirates is known as dysmegakaryocytopoiesis and it includes both dysplastic and non-dysplastic features. Dysplastic features are multiple separated nuclei, micromegakaryocytes and hypogranular forms. Non dysplastic features are immature forms, emperipolesis, budding (blebbing of cytoplasm on their surface), cytoplasmic vacuolization and bare nuclei. ${ }^{3}$

In myelodysplastic syndrome, dysplastic changes in megakaryocytes are seen along with thrombocytopenia. However, it can also be seen in non-myelodysplastic hematological conditions, as shown by various studies. ${ }^{7}$ The present study was undertaken to calculate the prevalence of various conditions associated with thrombocytopenia and to assess megakaryocytic alterations in various cases of thrombocytopenia. Dysplastic megakaryocytic alterations and their contribution to thrombocytopenia were also studied in non-MDS diseases so as to increase the diagnostic accuracy.

\section{MATERIALS AND METHODS}

This was a prospective study which included 132 patients, who underwent bone marrow aspiration from $14^{\text {th }}$ April, 2017 to $13^{\text {th }}$ April, 2018 in the department of Pathology, Tribhuvan University Teaching Hospital, Institute of Medicine, Maharajgunj, Kathmandu. All the bone marrow samples with thrombocytopenia which were diagnosed on hematology analyzer and confirmed by peripheral smears during the period of one year were taken for the study. Informed consent was taken from the subjects and ethical approval was taken from the Institutional Review Board.

Bone marrow aspiration was performed under aseptic conditions from iliac crest using Salah needle. All universal precautions were taken into consideration. The skin over the site was cleaned with betadine and $2 \%$ lidocaine was infiltrated into the skin, subcutaneous tissue and periosteum. About $0.3 \mathrm{ml}$ of marrow was aspirated using $10 \mathrm{ml}$ sterile needle. Smears were made immediately, air dried and stained with Wright stain. Megakaryocyte morphology was studied with a 100X objective. The number of the megakaryocytes was considered as normal: one megakaryocyte per one to three low-power fields, increased: more than two megakaryocytes per low-power field or decreased: one megakaryocyte per five to ten low-power fields. ${ }^{4}$ The morphological changes of megakaryocytes that were studied included nuclear segmentation, presence of immature forms, micromegakaryocytes, emperipolesis, cytoplasmic vacuolization, cytoplasmic budding, bare megakaryocytic nuclei and hypogranular forms. The number and morphology of the megakaryocytes in MDS as well as non-MDS related thrombocytopenia were assessed and compared. Statistical analysis like mean, median and descriptive analysis was performed using SPSS version 24 .

\section{RESULTS}

Of the 516 case of bone marrow aspiration reported in department of pathology from $14^{\text {th }}$ April, 2017 to $13^{\text {th }}$ April, 2018, 183 cases had thrombocytopenia. Fifty one cases were excluded from the study, as 42 cases had diluted smears and 9 cases had no megakaryocytes. A total of 132 cases $(25.5 \%)$ were included in the present study.

The age of the patients who presented with thrombocytopenia ranged from 2 years to 85 years old and most subjects were above 61 years accounting for 27 cases (20.5\%).

Thrombocytopenia was more common in males 
Table 1: Distribution of megakaryocytes in various hematological conditions with thrombocytopenia

\begin{tabular}{|c|c|c|c|c|}
\hline \multirow[b]{2}{*}{ Bone marrow impression } & \multicolumn{3}{|c|}{ Megakaryocyte number } & \multirow[t]{2}{*}{ Total } \\
\hline & $\begin{array}{c}\text { Normal } \\
(1 \mathrm{Mk} / 1 \text { to } 3 \mathrm{LPF})\end{array}$ & $\begin{array}{c}\text { Decreased } \\
(1 \mathrm{Mk} / 5-10 \mathrm{LPF})\end{array}$ & $\begin{array}{c}\text { Increased } \\
(>2 \mathrm{Mk} / \mathrm{LPF})\end{array}$ & \\
\hline Megakaryocytic thrombocytopenia & 35 & 0 & 33 & 68 \\
\hline Acute Leukemia & 5 & 11 & 0 & 16 \\
\hline Megaloblastic anemia & 10 & 0 & 3 & 13 \\
\hline Aplastic anemia & 0 & 12 & 0 & 12 \\
\hline MDS & 6 & 3 & 1 & 10 \\
\hline Multiple myeloma & 5 & 0 & 0 & 5 \\
\hline Leishmaniasis & 4 & 0 & 0 & 4 \\
\hline CML(Blast crisis) & 1 & 1 & 0 & 2 \\
\hline $\begin{array}{l}\text { Metastatic malignant small round } \\
\text { cell tumor }\end{array}$ & 0 & 1 & 0 & 1 \\
\hline CLL & 1 & 0 & 0 & 1 \\
\hline Total & 67 & 28 & 37 & 132 \\
\hline
\end{tabular}

Table 2: Dysplastic changes in various hematological conditions

\begin{tabular}{|c|c|c|c|c|}
\hline $\begin{array}{l}\text { Bone marrow } \\
\text { impression }\end{array}$ & (n) & Hypogranular forms (\%) & $\begin{array}{c}\text { Micro megakaryocyte } \\
(\%)\end{array}$ & $\begin{array}{c}\text { Multiple separated nuclei } \\
(\%)\end{array}$ \\
\hline $\begin{array}{l}\text { Megakaryocytic } \\
\text { thrombocytopenia }\end{array}$ & 68 & 0 & $14(20.58 \%)$ & $2(2.9 \%)$ \\
\hline Acute Leukemia & 16 & 0 & 0 & 0 \\
\hline Megaloblastic anemia & 13 & $1(7.6 \%)$ & $3(23.07 \%)$ & $4(30.76 \%)$ \\
\hline Aplastic anemia & 12 & 0 & 0 & 0 \\
\hline MDS & 10 & $2(20 \%)$ & $7(70 \%)$ & $1(10 \%)$ \\
\hline Multiple myeloma & 5 & 0 & 0 & 0 \\
\hline Leishmaniasis & 4 & 0 & 0 & 0 \\
\hline CML & 2 & 0 & $1(50 \%)$ & 0 \\
\hline $\begin{array}{l}\text { Metastatic malignant } \\
\text { small round cell tumor }\end{array}$ & 1 & 0 & 0 & 0 \\
\hline CLL & 1 & 0 & 0 & 0 \\
\hline Total & 132 & 3 & 25 & 7 \\
\hline
\end{tabular}

Table 3: Non dysplastic changes in various hematological conditions

\begin{tabular}{|c|c|c|c|c|c|c|}
\hline $\begin{array}{l}\text { Bone marrow } \\
\text { impression }\end{array}$ & (n) & $\begin{array}{l}\text { Immature forms } \\
(\%)\end{array}$ & $\begin{array}{c}\text { Cytoplasmic } \\
\text { vacuolization } \\
(\%)\end{array}$ & $\begin{array}{l}\text { Cytoplasmic } \\
\text { budding }(\%)\end{array}$ & Bare nuclei (\%) & $\begin{array}{c}\text { Emperipolesis } \\
(\%)\end{array}$ \\
\hline $\begin{array}{l}\text { Megakaryocytic } \\
\text { thrombocytopenia }\end{array}$ & 68 & $26(38.2 \%)$ & $1(1.4 \%)$ & 0 & $16(23.5 \%)$ & $3(4.4 \%)$ \\
\hline Acute Leukemia & 16 & 0 & 0 & 0 & 0 & 0 \\
\hline Megaloblastic anemia & 13 & $1(7.6 \%)$ & $1(7.6 \%)$ & $1(7.6 \%)$ & 0 & 0 \\
\hline Aplastic anemia & 12 & 0 & 0 & 0 & 0 & 0 \\
\hline MDS & 10 & $1(10 \%)$ & 0 & 0 & $4(40 \%)$ & 0 \\
\hline Multiple myeloma & 5 & 0 & 0 & 0 & & 0 \\
\hline Leishmaniasis & 4 & 0 & 0 & 0 & 0 & 0 \\
\hline CML & 2 & 0 & 0 & 0 & 0 & 0 \\
\hline $\begin{array}{l}\text { Metastatic malignant small } \\
\text { round cell tumor }\end{array}$ & 1 & 0 & 0 & 0 & 0 & 0 \\
\hline CLL & 1 & 0 & 0 & 0 & 0 & 0 \\
\hline Total & 132 & 28 & 2 & 1 & 20 & 3 \\
\hline
\end{tabular}




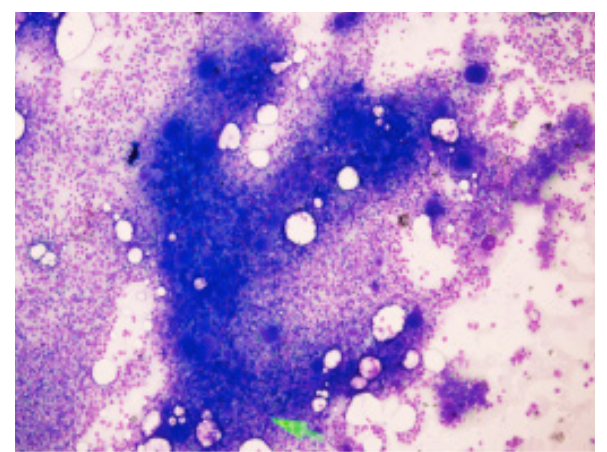

Figure 1: Bone marrow aspiration smear showing increased megakaryocytes in case of megakaryocytic thrombocytopenia (WrightGiemsa stain, X100).

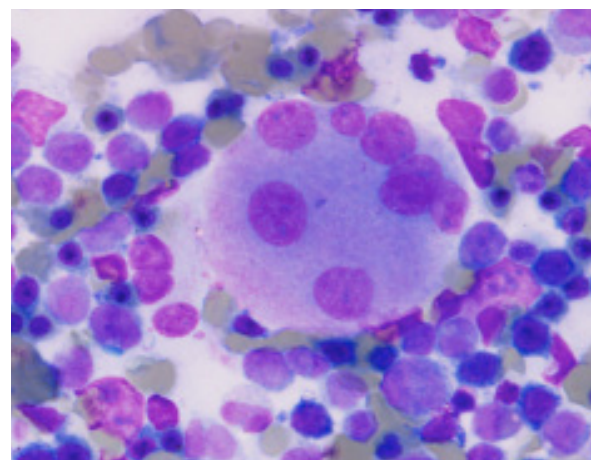

Figure 3: Bone marrow aspiration smear showing multiple separated nuclei in case of megaloblastic anemia (Wright-Giemsa stain, X1000).

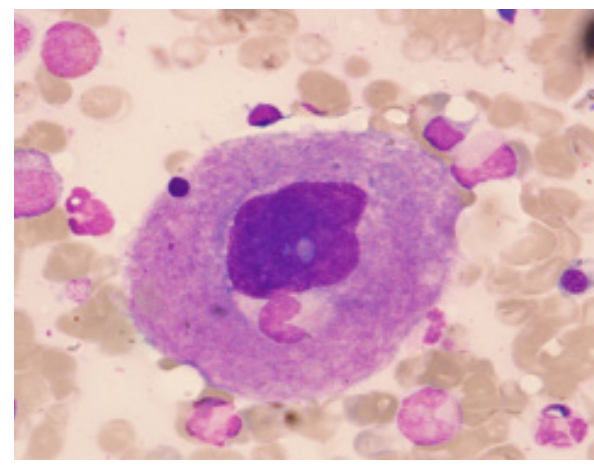

Figure 5: Bone marrow aspiration smear showing emperipolesis in case of megakaryocytic thrombocytopenia (WrightGiemsa stain, X1000).

accounting for 75 cases (57\%) than in females 57 cases (43\%). Among the 132 bone marrow aspirate samples, megakaryocytic thrombocytopenia was the most common cause of thrombocytopenia which was observed in 68 cases (51.51\%), followed by acute leukemia in 16 cases $(12.1 \%)$.

There was an increase in the number of megakaryocytes in 33 cases $(48.5 \%)$ of megakaryocytic thrombocytopenia (fig 1 ) and 3 cases (23\%) of megaloblastic anemia. 11 cases $(68.7 \%)$ of acute leukemia and 3 cases (30\%) of MDS had

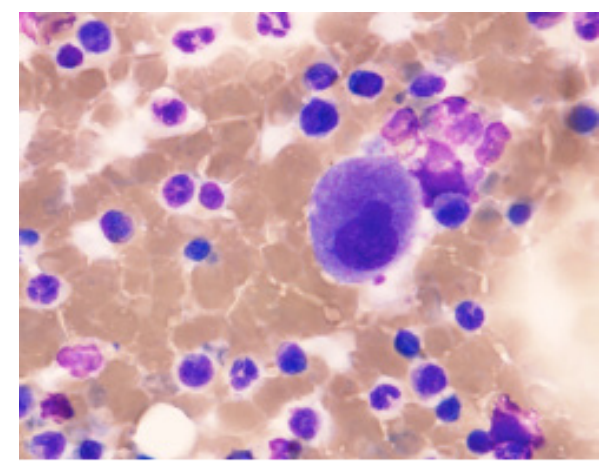

Figure 2: Bone marrow aspiration smear micromegakaryocyte in case of MDS (WrightGiemsa stain, X1000).

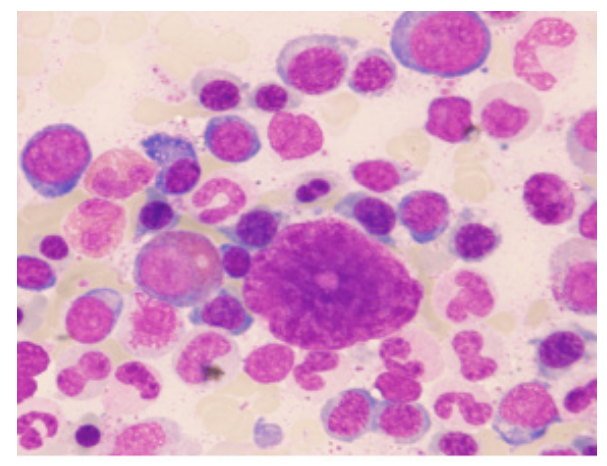

Figure 4: Bone marrow aspiration smear showing bare nuclei in case of megakaryocytic thrombocytopenia (WrightGiemsa stain, X1000).

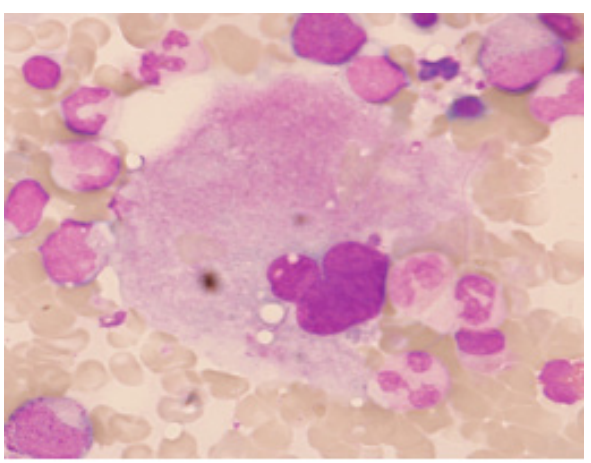

Figure 6: Bone marrow aspiration smear showing cytoplasmic vacuolization in case of megakaryocytic thrombocytopenia (WrightGiemsa stain, X1000).

decrease in number of megakaryocytes.

As shown in table 2, the most common dysplastic changes observed in the megakaryocytes were micro megakaryocytes (fig 2), which were observed in 14 cases $(20.58 \%)$ of megakaryocytic thrombocytopenia followed by in 7 cases of MDS (70\%) and 3 cases (23.07\%) of megaloblastic anemia. Multiple separate nuclei (fig 3) were most commonly observed in 4 cases $(30.76 \%)$ of megaloblastic anemia followed by in 2 cases $(2.9 \%)$ of megakaryocytic 
thrombocytopenia and 1 case (10\%) of MDS.

In this study, the most common non dysplastic changes in megakaryocytes observed were immature forms seen in 26 cases $(38.2 \%)$ and bare nuclei (fig 4$)$ in 16 cases $(23.5 \%)$ of megakaryocytic thrombocytopenia. Emperipolesis (fig 5) was noted in 3 cases (4.41\%) of megakaryocytic thrombocytopenia. Cytoplasmic vacuolization (fig. 6) was observed in one case of megakaryocytopenic thrombocytopenia and one case of megaloblastic anemia. The non dysplastic morphology observed has been tabulated in table 3.

\section{DISCUSSION}

Thrombocytopenia is the most common hematological disorder for which bone marrow aspiration is done. It may be an isolated finding or associated with pancytopenia. ${ }^{8}$ It is commonly seen in various hematological disorders including myelodysplastic syndromes (MDS) as well as various non-myelodysplastic hematological conditions. ${ }^{9}$ Dysplastic changes are well known in megakaryocytes in thrombocytopenia associated with MDS. However, they are also observed in megakaryocytes in non-myelodysplastic hematological conditions.

In the present study, the youngest patient was 2 years old and the oldest was 85 years old. The most common age group involved was 61 years and above accounting for 27 cases $(20.5 \%)$. In contrast, thrombocytopenia was seen more commonly in below 20 years $(57.9 \%)$ in a study conducted by Pokharel S. et al. ${ }^{8}$ It was observed that thrombocytopenia was slightly more common in males $(56.8 \%)$ than in females (43.2\%) which was in accordance to that in the similar study conducted by Muhury $\mathrm{M}$ et al (male: $63.2 \%$ and female: $36.8 \%$ ) and Gupta P et al (male:58\% and female:42\%).

In this study, the commonest cause of thrombocytopenia for which bone marrow examination was done was megakaryocytic thrombocytopenia seen in 68 cases (51.51\%). This was followed by acute leukemia seen in 16 cases $(12.1 \%)$ and megaloblastic anemia in 13 cases $(9.8$ $\%)$. Similarly, megakaryocytic thrombocytopenia was the commonest cause of thrombocytopenia in a study done by Pokharel S et al. This was followed by acute leukemia and aplastic anemia. Megaloblastic anemia and myelofibrosis were the least common causes ${ }^{8}$. Similarly, Gupta P et al also found ITP as the most common cause of thrombocytopenia followed by megaloblastic anemia and iron deficiency anemia. $^{3}$

Dysplastic megakaryocytes were appreciated in megakaryocytic thrombocytopenia, megaloblastic anemia and MDS. The most common dysplastic change observed was micro megakaryocyte observed in 25 cases $(18.93 \%)$ followed by multiple separate nuclei in 7 cases $(5.3 \%)$. Hypo granular forms were seen in 3 cases $(2.27 \%)$. Similarly, Neelima et al observed micro megakaryocytes in 25 cases $(32.0 \%)$, multiple separate nuclei in 17 cases $(21.7 \%)$ and hypo granular form was the least observed dysplastic feature seen in 7 cases $(8.9 \%){ }^{7}$

Immature forms and bare nuclei were the most common nondysplastic features seen in 28 cases $(21.21 \%)$ and 20 cases $(15.15 \%)$ respectively. Emperipolesis was observed in 3 cases $(2.27 \%)$, cytoplasmic vacuolization in 2 cases $(1.51 \%)$ and cytoplasmic budding in 1 case $(0.75 \%)$. Study done by Muhury $\mathrm{M}$ et al observed bare nuclei as the most common nondysplastic finding which was seen in 67 cases (46.5\%). This was followed by immature form in 58 cases (40.2\%), emperipolesis in 45 cases $(31.2 \%)$, cytoplasmic vacuolization in 21 cases $(14.6 \%)$ and platelet budding in 17 cases $(12.2 \%){ }^{9}$

Out of 68 cases of megakaryocytic thrombocytopenia, 33 cases $(48.5 \%)$ had increased number of megakaryocytes in bone marrow aspiration smears. The maximum number of megakaryocyte observed was 140/10 LPF. In contrast, Pokharel $\mathrm{S}$ et al found increase in the number of megakaryocytes in 15 cases $(88.3 \%)$ of megakaryocytic thrombocytopenia. ${ }^{8}$

The most common dysplastic change observed in megakaryocytic thrombocytopenia was micro megakaryocyte seen in 14 cases $(20.58 \%)$ followed by multiple separate nuclei in 2 cases $(2.9 \%)$. The most common non dysplastic changes were immature forms seen in 26 cases $(38.2 \%)$ and bare nuclei in 16 cases (23.5\%). Study done by Choudhary PK et al showed young, immature megakaryocytes in $94 \%$ (31 cases) of ITP cases. ${ }^{10}$ In contrast, hypolobulation (52.94\%) \& hypogranular forms (35.29\%) followed by cytoplasmic vacuolization were the most common morphological alterations found by Gupta $\mathrm{P}$ et al. ${ }^{3}$

Out of 16 cases of leukemia, 11 cases $(68.75 \%)$ showed decreased number of megakaryocytes. This corresponds to a study done by Vinayakamurthy S. et al where $65 \%$ cases showed decrease in number of megakaryocytes. ${ }^{11}$ Leukemic cells infiltrating the marrow may lead to decreased production. Chemotherapy, radiotherapy, and immunemediated destruction of megakaryocytes are the other causes which may result in decreased megakaryocytes. ${ }^{11}$ Morphology of megakaryocytes was normal in all 16 cases of acute leukemia in our study. In contrast, Vinayakamurthy S. et al found dysplastic changes in which $60 \%$ showed nuclear segmentation, $40 \%$ showed micro megakaryocytes, and $10 \%$ showed hypogranular forms. Immature forms (45\%), hypolobation $(40 \%)$, bare nuclei $(40 \%)$, emperipolesis $(5 \%)$, and budding $(10 \%)$ were the non-dysplastic features commonly encountered in cases of acute leukemia. ${ }^{11}$ Neelima et al also found dysplastic megakaryocytes, most common being micro megakaryocyte and multiple separate nuclei in $50 \%$ of cases, similar to study done by Choudhary et al. ${ }^{7,10}$ 
In the present study, out of 13 cases of megaloblastic anemia, 3 cases $(23.1 \%)$ had increased megakaryocyte count and 10 cases $(76.9 \%)$ had normal number of megakaryocytes. In contrast, $61.8 \%$ cases of megaloblastic anemia had increased megakaryocytes in a study done by Neelima et al. ${ }^{7}$ In megaloblastic anemia, dysplastic forms of megakaryocytes were seen in five cases $(38.4 \%)$ in contrast to that found by Muhury $\mathrm{M}$ et al $(75 \%)^{9}$. The most common dysplastic findings were multiple separate nuclei observed in 4 cases $(30.7 \%)$ and micro megakaryocytes in 3 cases $(23.07 \%)$. Non dysplastic changes found were cytoplasmic budding, cytoplasmic vacuolization and immature forms noted in 1 case (7.6\%). Similarly in a study done by Choudhary PK et al, the most common dysplastic changes were multiple separate nuclei in 18 cases $(40.9 \%)$ and micro megakaryocyte in 5 cases $(11.4 \%)$ which were also found by Muhury $\mathrm{M}$ et al. ${ }^{9}, 10$ Wickramasinghe also observed megakaryocytes with separation of nuclear lobes and nuclear fragments and attributed this to diminished DNA synthesis leading to nuclear maturation defect. ${ }^{12}$

Out of 10 cases of MDS, 1 case (10\%) showed increased megakaryocyte count and 3 cases (30\%) showed decreased count. Dysplastic changes noted were micro megakaryocytes in 7 cases $(70 \%)$, hypogranular forms in 2 cases $(20 \%)$ and multiple separate nuclei in 1 case $(10 \%)$. Non dysplastic changes noted were bare nuclei in 4 cases $(40 \%)$ and immature form in 1 case $(10 \%)$. Similarly, Tejinder Singh et al observed micro megakaryocytes in 66\% cases. But hypogranular forms were noted in $100 \%$ cases, bare megakaryocytes in $16.6 \%$ cases and immature forms in $50 \%$ cases. $^{4}$

In current study, there were 12 cases of aplastic anemia with decreased megakaryocyte count in all cases. Similarly, Dameshek et al found decreased megakaryocyte count and increased count of lymphocytes in the bone marrow of the aplastic anemia patients, which showed failure of hematopoietic function. ${ }^{13}$ Morphology of megakaryocytes were normal in all cases of aplastic anemia in our study similar to that observed by Tricot et al and Dameshek et al. ${ }^{13,14}$

Hence, this study shows that dysplastic megakaryocytes are found both in MDS as well as non-MDS related thrombocytopenia. The presence of dysplastic changes in megakaryocytes should not lead to diagnosis of MDS and other hematological conditions should be considered in differential diagnosis. Understanding the morphological changes in the bone marrow aspirates helps in the diagnosis of various hematological conditions associated with thrombocytopenia.

\section{CONCLUSIONS}

Many similarities in morphological changes of megakaryocytes were observed in various hematological conditions. The diagnostic accuracy for various causes of thrombocytopenia can be increased by understanding the morphological changes in megakaryocytes in bone marrow aspiration smears and correlating the findings with the patient's clinical findings and other hematological parameters. This can further enable proper therapeutic interventions.

\section{Recommendations}

This study was done in limited number of cases and with limited time duration. In every cases of thrombocytopenia, morphological findings of megakaryocytes in bone marrow aspiration smears should be correlated with patient's clinical findings and other hematological parameters which further helps in making diagnosis. Further, cytogenetics and molecular studies whenever needed can help in evaluation of patients in regard to prognosis and determination of clonality.

\section{Conflict of interest: None}

\section{REFERENCES}

1. Anderson SC, Poulsen KB. Blood cells. Anderson's atlas of hematology. 1st ed. Lippincott Williams and Wilkins; 2003. p.3-154

2. Patel SR, Hartwig JH, Italiano JE, Jr. The biogenesis of platelets from megakaryocyte proplatelets. J Clin Invest. 2005;115(12):3348-54. $\underline{\text { Crossref }}$

3. Gupta P, Goswami A, Chavda J, Goswami N, Shah S. Study of Megakaryocytes in Bone Marrow Aspiration Smears in Patients with Thrombocytopenia. IOSR J Dent Med Sci Ver III. 2015;14(6):2279861. Crossref

4. Bhasin TS, Sharma S, Manjari M, et al. Changes in megakaryocytes in cases of thrombocytopenia: bone marrow aspiration and biopsy analysis. J Clin Diagn Res. 2013;7(3):473-9. $\underline{\text { Crossref }}$

5. Izak M, Bussel J. Management of thrombocytopenia. F1000Prime Rep. 2014;6-45. $\underline{\text { Crossref }}$

6. Erkurt MA, Kaya E, Berbel I, Koroglu M. Thrombocytopenia in adults: Review Article. Journal of Hematology. 2012;1:44-53. $\underline{\text { Crossref }}$

7. Tirumalasetti N, Challa NR. Bone marrow aspiration study of megakaryocytic alterations in non myelodysplastic syndrome related thrombocytopenia. Indian J Pathol Oncol. 2016;3(4):587-92. $\underline{\text { Crossref }}$

8. Pokharel S, Upadhyaya P, Karki S, Paudyal P, Pradhan B, Poudel P. Megakaryocytic alterations in thrombocytopenia: A bone marrow aspiration study. J Pathol Nepal. 2016;6(11):914-21. $\underline{\text { Crossref }}$

9. Muhury M, Mathai AM, Rai S, Naik R, Pai MR, Sinha R. Megakaryocytic alterations in thrombocytopenia: a bone marrow aspiration study. Indian J Pathol Microbiol. 2009;52(4):490-4. $\underline{\text { Crossref }}$

DOI : 10.3126/jpn.v9i2.25408 
10. Choudhary P, Sing S, Basnet R. Study of megakaryocytes in bone marrow aspiration smears in patients with thrombocytopenia. $\mathrm{J}$ Pathol Nepal. 2013;3(6): 476-81. $\underline{\text { Crossref }}$

11. Vinayakamurthy S, Potluri R, Shivajirao P, Singh R, Pujahari R, Maniketh I. A study of megakaryocyte morphology in bone marrow aspiration smears of cases of thrombocytopenia. Med J Dr DY Patil Univ. 2017;10(1):51. $\underline{\text { Crossref }}$

12. Wickramasinghe SN. Morphology, biology and biochemistry of cobalamin- and folate-deficient bone marrow cells. Baillieres Clin Haematol. 1995;8(3):441-59. Crossref
13. Dameshek W, Miller EB. The megakaryocytes in idiopathic thrombocytopenic purpura, a form of hypersplenism. Blood. 2016;127(1):3-3. Crossref

14. Tricot G, Vlietinck R, Boogaerts MA, Hendrickx B, et al. Prognostic factors in the myelodysplastic syndromes: importance of initial data on peripheral blood counts, bone marrow cytology, trephine biopsy and chromosomal analysis. Br J Haematol. 1985;60(1):19-32. $\underline{\text { Crossref }}$ 